Please send trade news information and illustrations to Arveen Bajaj at the BDJ, 64 Wimpole Street, London W1G 8YS. Trade news is supplied as a service to the reader and does not imply endorsement by the BDJ. Normal and prudent research should be exercised before purchase of use of any product mentioned.

\section{TRADE NEWS}

WHAT'S NEW

\section{New addition}

The latest addition to the Fortoss bone substitute family has been introduced. Fortoss VITAL does not contain any animal tissue and is the first synthetic bone substitute that closely mimics the characteristics of human-bone tissue invivo. It is mixed into a paste which then sets hard into the defect to form a cell occlusive matrix, meaning that no membrane is required. Over a period of months it is replaced by host bone, which is then suitable for implant cases. The product is available from Swallow Dental Supplies.

Reader response number 50

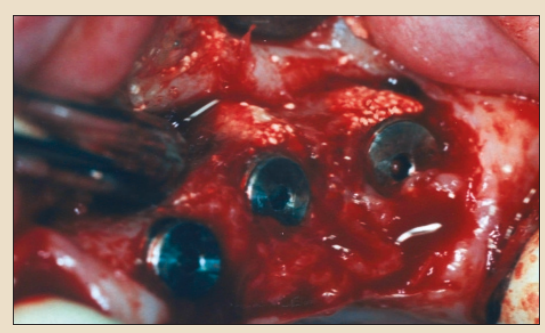

\section{Effective disinfection}

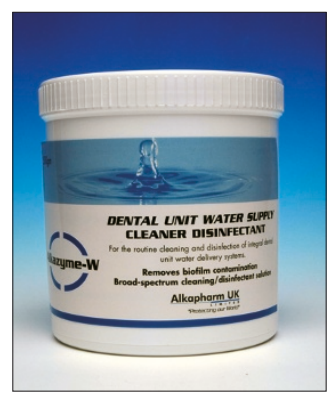

Alkazyme-W is a new, combined cleanser and disinfection agent for use in the routine decontamination of chair-side integral water supply units in dental surgeries.

It dissolves proteins, and given a minimum five minute contact time will breakdown bio-films, leaving all internal surfaces clean and disinfected. It is available in pots of 500grams of concentrated powder supplied with a $5 \mathrm{mg}$ dosing spoon, and each $5 \mathrm{gm}$ dose makes 1 litre of full strength solution. Alkapharm is offering all dentists the opportunity to test the level of contamination in the water dispensed at chair-side (before and after cleaning) free of charge by visiting www.alkapharm.co.uk. Reader response number 51

\title{
Relief for sensitive teeth
}

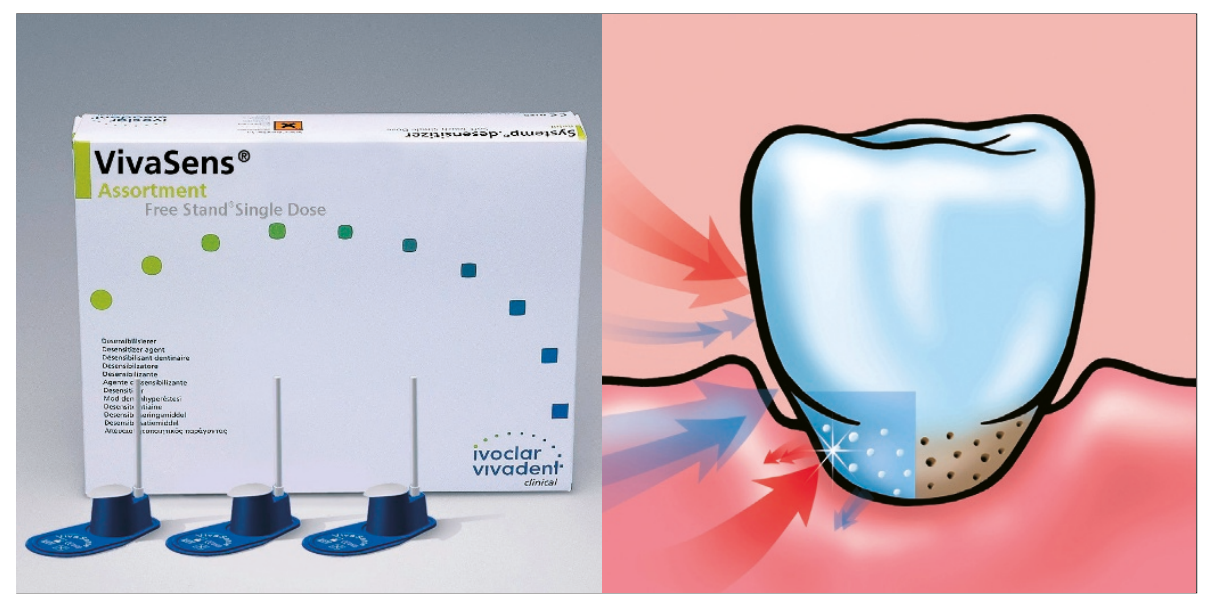

VivaSens, a new desensitizer can offer quick relief for adults who suffer from sensitive teeth, according to Ivoclar Vivadent.

The film-like varnish provides a protective shield against external stimuli, sealing exposed root surfaces, whilst tightly blocking open dentine tubuli via the precipitation of calcium ions and proteins in the dentinal fluid. Potassium fluoride offers additional protection.

It can be used to reduce hypersensitivity due to gingival recession, bleaching, professional tooth-cleaning as well as scaling and root-planing. It may also be used preventively in patients with sensitive teeth.

Reader response number 52

\section{Making teeth fun}
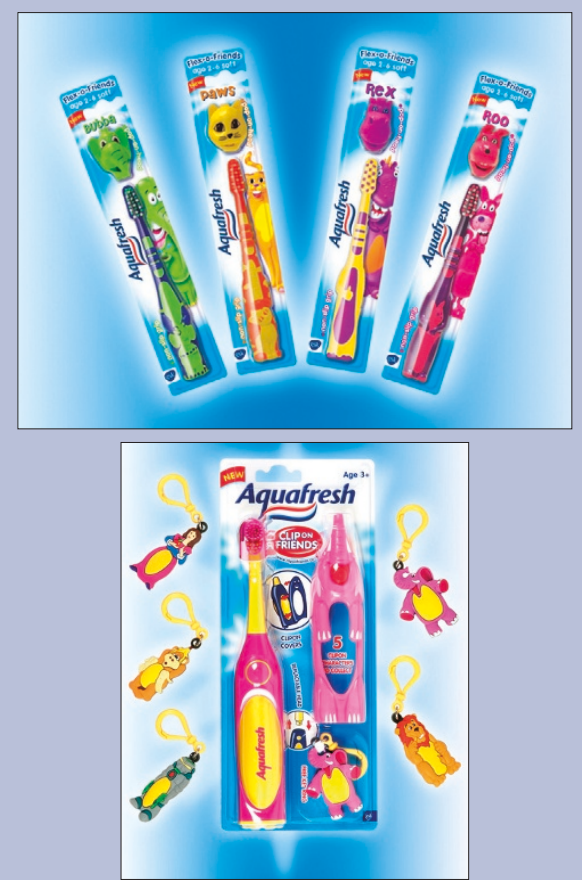

GlaxoSmithKline (GSK) have expanded their Aquafresh toothbrush range for children.

The dual action, children's battery powered toothbrush, Aquafresh Clipon Friends, consists of five Clipon characters.

Each character clips onto the front of an Aquafresh childrens' powerbrush and can be swapped for another character in order to retain interest in the brush beyond the original purchase.

GSK has also added two new Flex-oFriends characters to its children's toothbrush rang. Paws and Rex have been joined by Roo the Kangaroo and Tusks the Elephant.

The range is designed to encourage children aged 3-8 years to brush their teeth properly and features a compact head with soft texture filaments, a child size rubber grip handle and a flexible neck to help absorb excess brushing pressure. Reader response number 53 